\section{DISEÑO DE ESTACIONES DE AUTOBUSES}

\section{Vicente Olalla}

Dr. Ingeniero de C.C.P.

Subdirector General de.

Infraestructura del

Transporte Terrestre

144-32

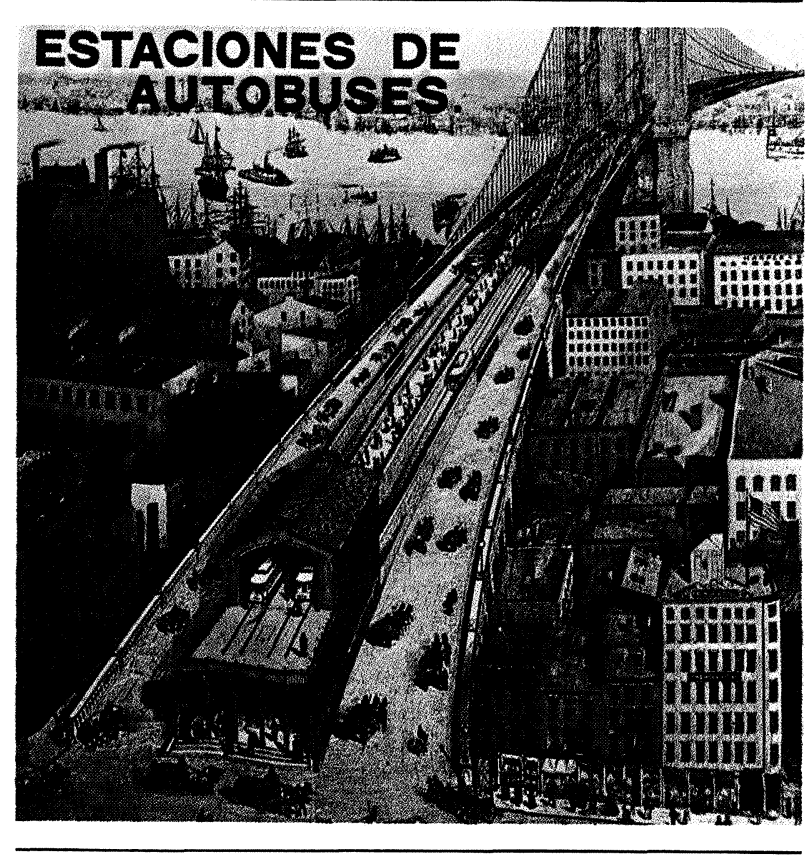

1. PREAMBULO

En el número 289 (abril 1977) de esta misma Revista, se publicó un artículo sobre aspectos generales de las estaciones de autobuses mencionando tres de ellas: Valladolid, Avila y Salamanca, construidas y puestas en explotación por el Ministerio de Obras Públicas, a través de la Dirección General de Transportes Terrestres, cuya continuidad ha sido depositada en la Dirección General de Infraestructura del Transporte del Ministerio de Transportes, Turismo y Comunicaciones.

Transcurrido suficiente tiempo y construidas varias estaciones de autobuses más de acuerdo con los planes previstos de la Administración sobre los transportes por carretera - que han pasado a depender del Ministerio de Transportes, Turismo y Comunicaciones desde su creación-, se ha considerado oportuno por la Dirección de la Revista ampliar la información sobre los aspectos examinados en el primitivo artículo, presentando a continuación varios ejemplos de estaciones de autobuses construidas por la Dirección General de Infraestructura del Transporte.

\section{LEGISLACION}

La Legislación Española sigue siendo sustancialmente la misma que entonces, dado que, en este aspecto, se ha mostrado eficaz dentro de su simplicidad y ha permitido la construcción de las estaciones que han sido solicitadas por las autoridades locales competentes, dentro de las que se consideran necesarias. Con los diversos Estatutos de Autonomia se producirán cambios en el proceso de gestación de las estaciones dado que una de las competencias que pasan en primer lugar a los Entes Autonómicos es la de los transportes; no obstante, y dado que el sistema de transporte colectivo en autobús es hoy por hoy insustituible, no deben existir dudas en cuanto a que seguirán construyéndose a pesar de los desajustes y prioridades presupuestarias que puedan producirse. Existen dos motivos principales: la necesidad de organizar la circulación de los autobuses interurbanos por las ciudades cada vez más constreñidas por las exigencias de la circulación rodada ciudadana y la conveniencia de prestar a los viajeros mayores facilidades y comodidades.

\section{VIGENCIA DE LAS ESTACIONES DE AUTOBUSES}

España es uno de los paises que, dentro de Europa, punto obligado de referencia para nosotros, ha desarrollado más la construcción de estaciones de autobuses, encabezando la lista de las naciones en número de ellas, si bien el autor dispone de datos totales que le permitan afirmarlo a ciencia cierta.

TRANSPORTE DE VIAJEROS EN AUTOBUSES, AUTOCARES Y TROLEBUSES (Viajeros $\times$ km, en millones)

\begin{tabular}{|l|c|c|c|}
\hline & 197 & 1978 & 1979 \\
\cline { 2 - 4 } ALEMANIA ORIENTAL & 25,11 & 25,41 & 25,58 \\
AUSTRIA & 12,53 & 12,66 & 12,91 \\
ESPANA & 28,87 & 31,30 & 31,00 \\
FINLANDIA & 7,6 & 7,6 & 7,75 \\
GRAN BRETANA & 53,00 & 52,00 & 52,00 \\
HOLANDA & 9,70 & 11,90 & 12,37 \\
HUNGRIA & 14,60 & 27,20 & 30,40 \\
NORUEGA & 3,72 & 3,99 & 3,93 \\
POLONIA & 48,67 & 48,95 & 47,69 \\
URSS & 344,48 & 361,54 & 376,00 \\
YUGOSLAVIA & 36,44 & 37,08 & s.d. \\
\hline
\end{tabular}


Con la intención de informar sobre el desarrollo de los viajeros por carretera que usan el autobús en sus viajes, se incluye una tabla con datos entresacados de la Memoria del año 1980, confeccionada por el Instituto de Estudios de Transportes y Comunicaciones.

Puede observarse que, en todos los paises que para 1979 han suministrado datos, se advierte un incremento de vehículo $/ \mathrm{km}$ y viajeros $/ \mathrm{km}$ de $10 s$ automóviles; en los autobuses; todos los paises, excepto Polonia, España y Gran Bretaña, también han experimentado aumentos. Al mismo tiempo, España ha tenido el mayor incremento en automóviles: un $5 \%$ en vehículo $/ \mathrm{km}$ y en viajero $/ \mathrm{km}$.

Esta lista es muy incompleta, echándose en falta - como principal pais con quien compararse- a Italia, pero da una idea del volumen de esta modalidad de transporte.

La principal consecuencia que se deduce de estos datos de la tabla es que, en España, la modalidad por carretera en medios colectivos es aún muy pequeña. Si se extendieran los cálculos a todos los vehículos, incluyendo los privados, se obtendria una clasificación análoga, lo que significa que es normal la relación entre el total de viaje$\mathrm{ros} / \mathrm{km}$ y el de viajeros $/ \mathrm{km}$ en autobús.

Ahora bien, es muy posible que las incidencias derivadas del alza en el coste del petróleo y el subsiguiente tratamiento de las economias lleven a la potenciación de los viajes colectivos.

En resumidas cuentas:

a) en España aún es pequeño, comparado con el valor medio europeo, el número de personas que utilizan el autobús como medio de transporte interurbano;

b) los servicios interurbanos de autobuses son unos servicios baratos, siendo el autobús el medio más eficaz desde el punto de vista energético.

Por ello es muy probable que aumente el número de viajeros $\times \mathrm{km}$ de este modo de transporte, una vez que se alcance el equilibrio roto por la subida del petróleo y de las crisis económicas que han hecho disminuir la rentabilidad de este servicio y, por ende, algún deterioro en el mismo.

Por otra parte, ha de considerarse la creciente preocupación tanto de las autoridades como de la misma sociedad, común a aquellos paises en los que la motorización privada está altamente generalizada, por aquellos que no pueden disponer personalmente de coche, fundamentalmente ancianos, niños, minusválidos, y económicamente débiles y la consiguiente necesidad de proporcionarles transportes públicos que les garantice un minimo de movilidad, siendo especialmente aguda esta necesidad en el caso de las zonas rurales en la que los servicios de transporte público aún no cumplen con sus posibilidades.

Estas razones, unidas a las expuestas en el número 289 de esta Revista, que continúan vigentes en todos sus detalles, hacen pensar que es logica la continuación de la politica emprendida de la construcción de estaciones de autobuses.

\section{DISEÑO DE ESTACIONES}

No se pueden dar pautas de obligado cumplimiento a la hora de especular sobre el diseño de una estación de autobuses puesto que debe dejarse libertad a la imaginación sobre la necesidad de adaptarse a las dimensiones, forma y situación del terreno previsto, pero han de tenerse en cuenta las posibilidades de la red viaria adyacente.

De los diversos proyectos redactados por el autor de este artículo y de los numerosos diseños que han quedado sin ser desarrollados, podrían distinguirse los dos que a continuación se comentan, considerando que pueden servir de prototipos. Han sido elegidos en primer lugar por su simplicidad de disposición, que ha servido de base a la redacción de proyectos cuyas obras han sido construidas y están en funcionamiento; y, en segundo lugar, porque son de aquellos por los que, tanto los viajeros como los autobuses, acceden a la estación desde la misma calle, que es el caso más común que se da en la realidad además de ser, por ello, del tipo que más espacio necesita.

Sorprendentemente, la superficie por dársena es similar en ambos casos, cuando cabia esperar una mayor diferencia.

\section{TAMAÑO DE LAS ESTACIONES}

Podemos dividir las estaciones según el número de dársenas en dos clases:

1) de menos de 10 dársenas,

2) de más de 10 dársenas.

En las estaciones mayores, el problema principal se presenta a la hora de situar las dársenas de forma que ocupen el menor espacio posible para que el viajero no tenga que recorrer mucho espacio; hay también que economizar la superficie necesaria y optimizar el aprovechamiento de la disponible. En las estaciones menores puede plantearse el problema inverso: crear suficiente espacio para el edificio, sin que la superficie total aumente innecesariamente, sobre todo si se prevé una cafetería y algunos locales comerciales.

No existe limite inferior para el número de dársenas; pero por debajo de 10 dársenas debe simplificarse el edificio al limite, puesto que difícilmente puede ser rentable su explotación. 


\section{ESTACION TIPO GRANDE}

Las dársenas están desarrolladas rodeando el edificio que es de forma rectangular, de modo que permita el desarrollo de las dársenas en la mayor parte de su perimetro. En general, su posición respecto a la zona de autobuses depende de las posibilidades del terreno disponible.

Básicamente existen dos soluciones optimas, con superficie mínima dado el número de dársenas necesarias en una sola planta.

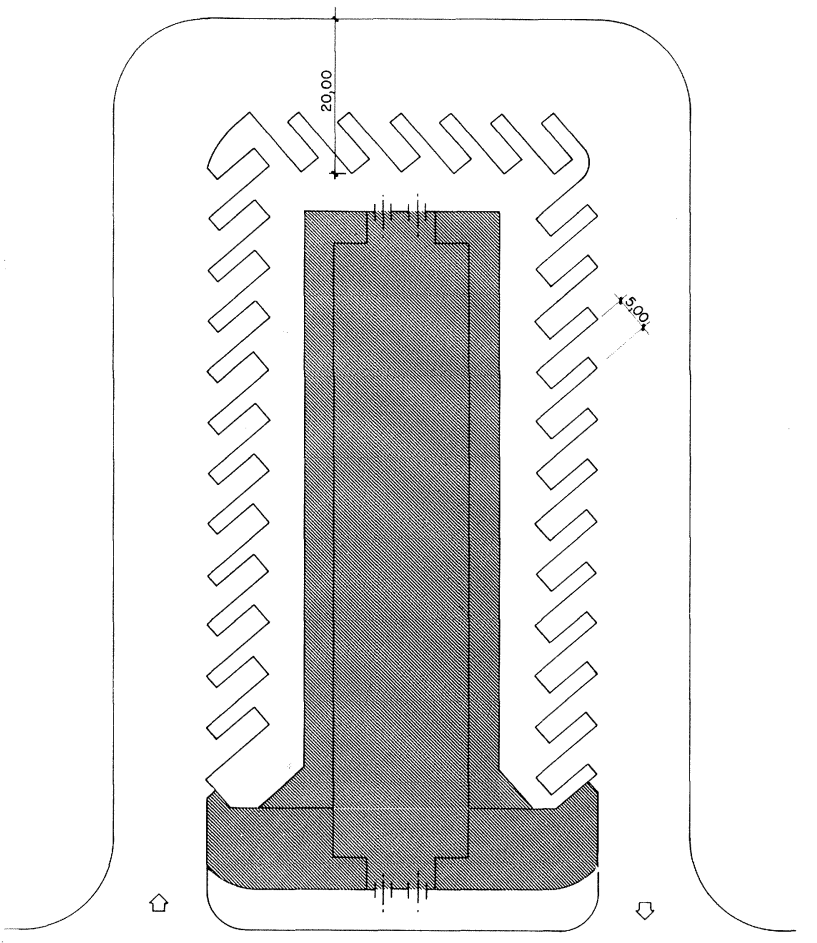

La primera solución deja inutilizado para colocar dársenas, uno de los lados cortos; la segunda, uno de los largos. Por el contrario, la fachada de la primera es inferior a la de la segunda $y$, por lo tanto, disminuye el número de locales comerciales con aprovechamiento independientes de la estación.

Como los ingresos procedentes del alquiler de los locales comerciales son necesarios para la rentabilidad de la explotación, esta segunda solución debe considerarse superior a la primera.

En esta última, la distancia que debe recorrer el viajero que vaya directamente desde la calle al autobús o viceversa debe ser la minima posible, para lo cual se prevén enfrentadas las dos puertas, de entrada desde la calle y de paso a dársenas.

La linea definida por los ejes de ambas puertas divide el edificio en dos partes, permitiendo colocar en una de ellas las taquillas, información, aseos y cafetería y, en la otra zona, de descanso, equipajes y locales comerciales, asi como las of $i-$ cinas de la administración y de las empresas concesionarias del transporte.

La motivación de esta división parece clara: en la primera, se incluyen instalaciones imprescindibles donde, por otra parte, es interesante no demorarse; la segunda es más apacible (la prisa no es necesaria) y, normalmente, no es imprescindible pasar por ella. La cafeteria se sitúa en la primera para que esté al alcance de todo el mundo, pero debe estar suficientemente aislada del vestibulo, evitando, desde luego, poner el mostrador en él.

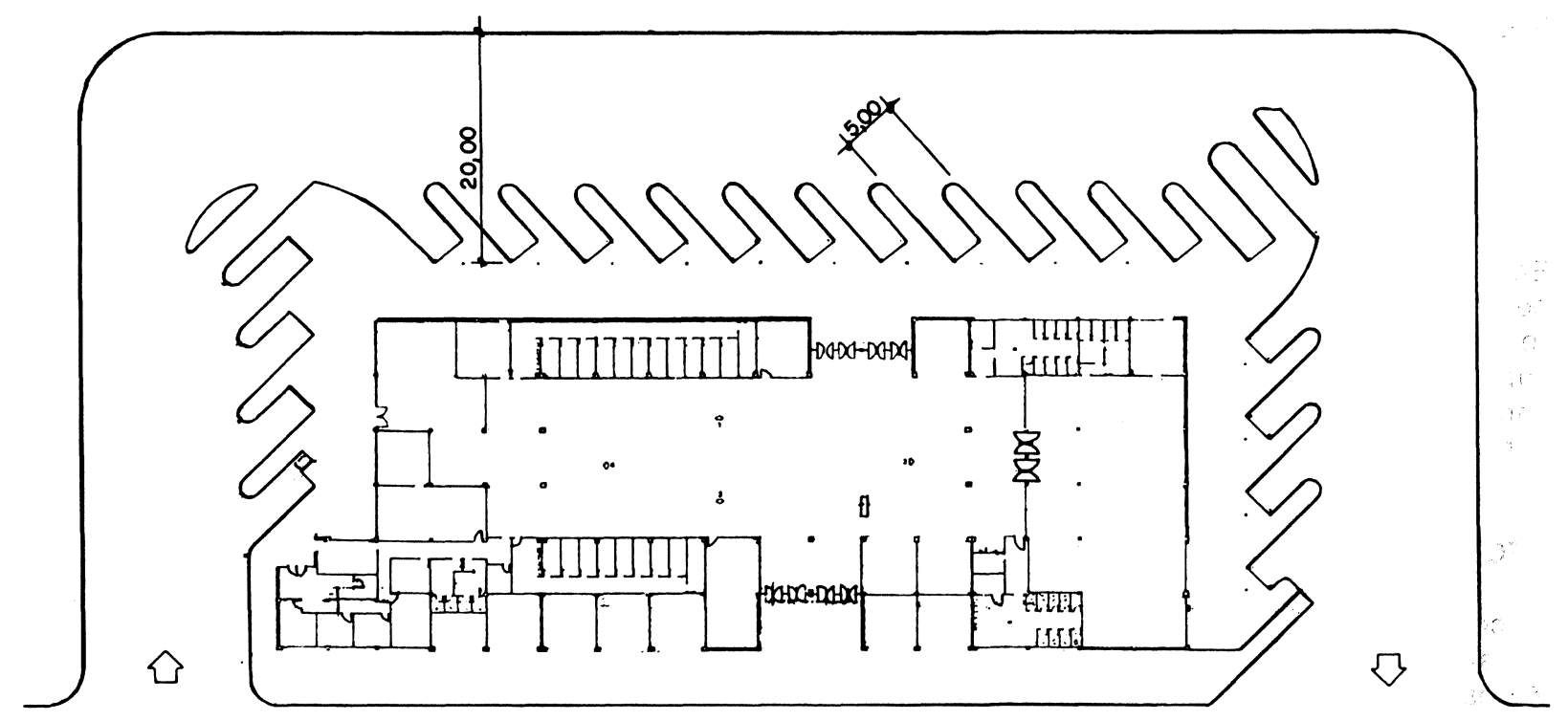




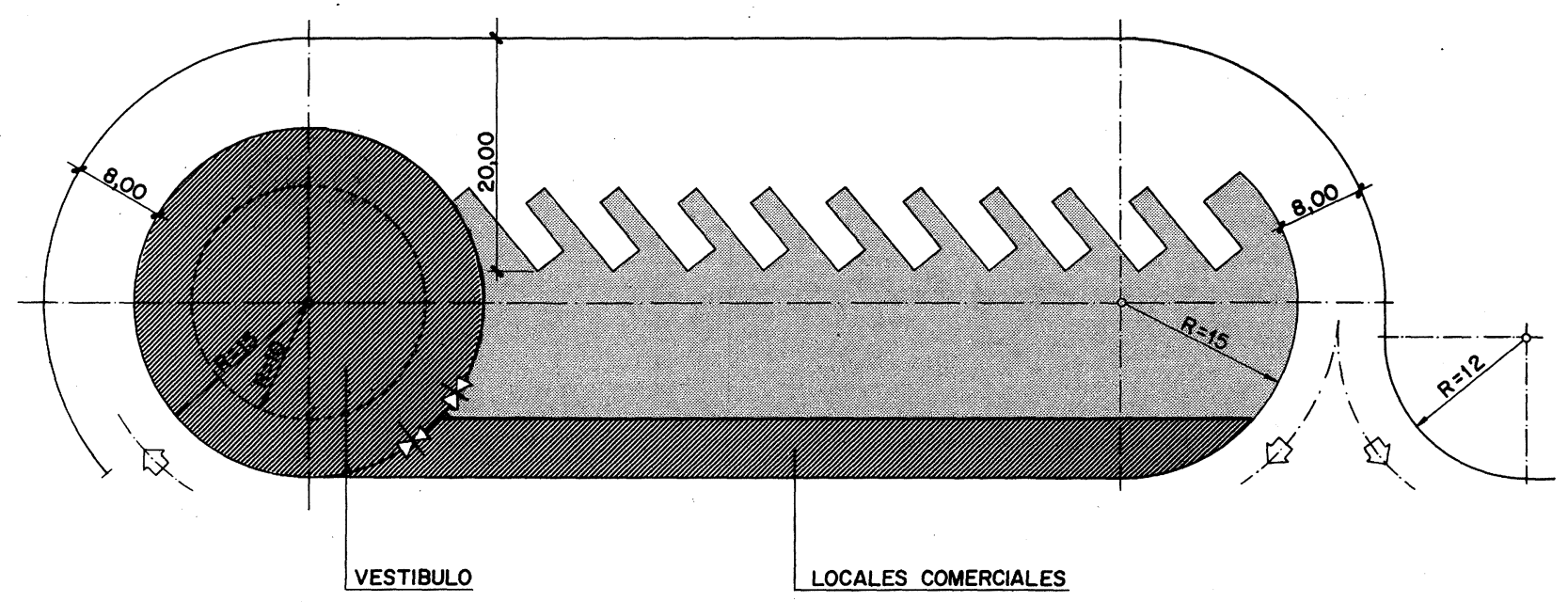

En el diseño propuesto se ha empleado el estacionamiento de autobús del tipo dársena por ser el que, normalmente, permite el mayor número de estacionamientos simultáneos dada una superficie disponible preestablecida.

La esencia del diseño consiste en los siguientes puntos:

\section{1. ${ }^{\circ}$ Que el autobús haga parte de su maniobra a} costa de la acera.

2. ' Se aprovecha la "zona muerta" que deja el autobús, al girar con el radio minimo posible, para instalar alli gran parte del edificio de viajeros.

3. No importa colocar el edificio y sus accesos de forma descentrada respecto a las dársenas, como seria de desear dado que las distancias a recorrer por los viajeros siguen siendo pequeñas puesto que también es pequeño el número de dársenas.

En el diseño presentado, que no tiene instalaciones para lavado, engrase y pequeño mantenimiento por no ser rentable y ni siquiera aconsejable, la superficie usada es de $4.800 \mathrm{~m}^{2}$, que para diez dársenas da una superficie unitaria de $480 \mathrm{~m}^{2}$ por dársena.

\section{NECESIDADES GENERALES}

A continuación se presenta una relación no exhaustiva pero si bastante completa de las necesidades a cubrir en una estación de autobuses.

\section{Edificio de viajeros}

- acceso peatonal desde la calle independiente del de autobuses;

- vestibulo;

- taquillas;

- equipajes: Manipulación, consigna, facturación;

- aseos;

- información;

- cafetería;

- restaurante.

\section{Zona de dársenas}

- accesos de autobuses;

- zonas de maniobra y circulación;

- dársenas;

- control;

- porteria;

- zona de espera;

- oficinas de empresas administrativas; 
- correos;

- periódicos;

- botiquin;

- policia;

- locales comerciales;

- instalaciones: eléctricas, de megafonia, calefacción, pararrayos, etc.;

- instalaciones: subestación, eléctricas, lavado, engrase, central de calefacción;

- cerramientos.

\section{ANCHO DE CARRIL}

Uno de los elementos, no muy definidos y que son muy importantes a la hora de proyectar una estación, es el del radio de giro minimo de los autobuses que debe ser empleado.

Lo normal es referirse al radio del bordillo o marca interior del carril.

La cifra utilizada habitualmente ha sido de 15 metros; pero, en no pocas ocasiones, será preciso emplear un radio inferior cuya medida no debe bajar de 12,5 metros.

La utilización de estos valores ha demostrado que son suficientes y no han planteado problema alguno con los tipos de autobuses que se emplean en España.

Estas cifras deben aumentar algo cuando en lugar de emplearse bordillo exterior y acera, que pueda sobrepasar el morro del autobús, existe un obstáculo no rebasable a causa del inevitable "efecto pared".

Con el radio está muy relacionada la anchura del carril. El autor emplea la siguiente escala:

\begin{tabular}{|c|c|}
\hline Radio $(\mathbf{m})$ & Anchura $(\mathbf{m})$ \\
\hline 12,5 & 8 \\
13 & 7,6 \\
15 & 6,5 \\
17 & 5,9 \\
20 & 5,3 \\
25 & 4,7 \\
30 & 4,4 \\
\hline
\end{tabular}

Una fórmula aproximada que da la anchura en función del radio interior del carril, si es rebasable el borde exterior, puede ser la siguiente:

$$
A=3,3+\frac{26}{R-6,95}
$$

donde:

$A=$ Anchura de carril, en metros.

$R=$ Radio del borde interior del carril, en metros.

Normalmente, el carril no tiene por qué ser de anchura uniforme por lo que estos datos servirán para diseñar los trazados de los bordillos o lineas exteriores de una forma proyresiva y armónica.

Dado que la estación va a ser usada por un gran número de autobuses, el ancho del carril no debe bajar del adoptado para 30 metros. Es preciso dejar alguna holgura porque aunque los conductores son profesionales, algunos no conocen las instalaciones. Por otro lado, debe evitarse en el diseño la existencia de carriles de entrada.

\section{FORMA Y DIMENSIONES DE LAS DARSENAS}

La forma más utilizada en los diseños del autor ha sido la que a continuación se detalla. Exige maniobra del autobús sólo a la salida que hace marcha atrás y permite el empleo de sus dos puertas. Dependiendo del ángulo ajustable de la dársena con el andén, puede obtenerse la longitud minima de éste, lo cual es muy importante dadas la limitación de dimensiones que suele haber.

La anchura minima de la dársena, que coincide con la normalmente empleada, es de 3,00 metros y la acera peatonal no debe tener una anchura menor de 2,00 metros, siendo $1,70 \mathrm{~m}$ el limite minimo utilizable.
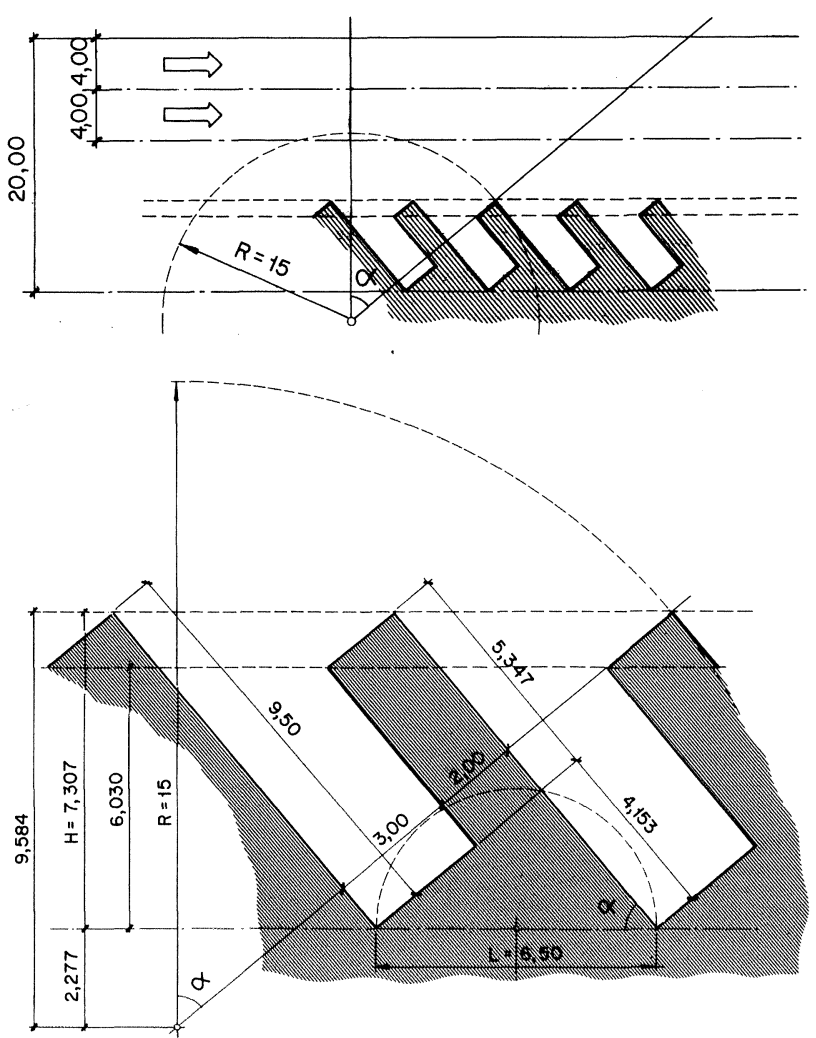
A continuación se detallan aspectos del diseño de algunas de las instalaciones.

\section{PASILLO COMUN A TAQUILLAS}

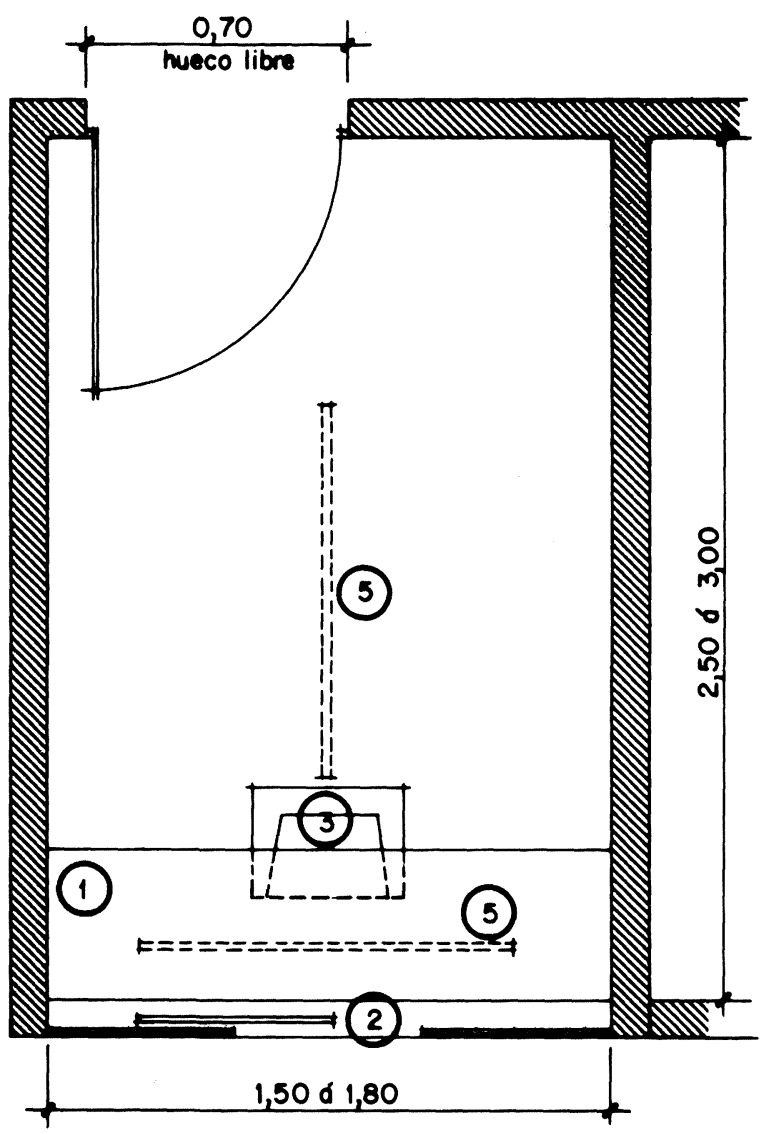

VESTIBULO

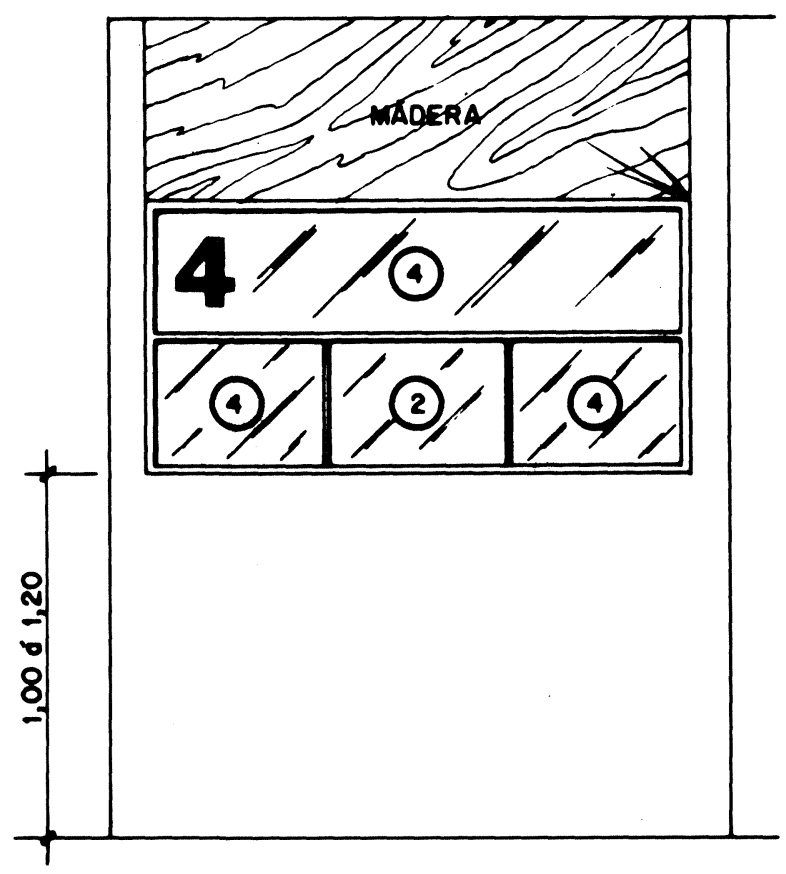

1. - Mesa de 0,40 $\mathrm{m}$ de ancho. 2. - Taquilla con puerta corredera para no ocupar espacio en la mesa. 3. - Silla sobre el suelo o posible tarima. 4. - Cristal fijo. 5. - Lámpara fluorescente.

\section{Taquillas}

En el n. 289 de la Revista se daban algunas ideas básicas para calcular el número de taquillas necesarias, dependiendo de las empresas transportistas existentes y del número de dársenas de la estación.

Las dimensiones de cada taquilla deben de ser las minimas posibles para su uso y deben colocarse adosadas "en bateria", con un pasillo posterior que dé servicio a todas ellas.

Las dimensiones minimas, de 1,5 a 1,8 metros de frente por 2,50 a 3,00 metros, permiten colocar el mayor número posible de ellas en el menor espacio y no deben ser usadas como oficinas de las empresas transportî́s tas.

El pasillo posterior permite independizarlas del tráfico de personas, puesto que el viajero no debe tener acceso a ellas más que a través de la ventanilla o mostrador y debe existir un local común a todas donde poder guardar el billetaje e, incluso, donde tener una caja fuerte.

\section{Equipajes}

Las necesidades de espacio para los equipajes están disminuyedo de una forma irreversible, pues los viajeros los transportan en menor medida y las empresas transportistas favorecen esa intención porque, al renunciar a llevar el equipaje en la baca, el espacio del autobús destinado a su transporte está muy limitado.

\section{FINAL}

El tema de este artículo es prácticamente inagotable $y$, en el fondo, lo que importa es el ingenio del proyectista cuyas felices ideas sólo pueden obtenerse del mucho tiempo dedicado al estudio y de su experiencia.

El conjunto de estaciones ya construidas que se presentan a continuación es un ejemplo de ello y con su recopilación se pretende dar a los demás proyectistas no sólo un libro de consulta sino lo que es más importante: una fuente de ideas que, a no dudar, serán superadas y ampliadas en futuras realizaciones.

\section{NOTA DE LA REDACCION}

Reproducimos, a continuación, el artículo del mismo autor publicado en el $n$. $^{\circ} 289$ de esta Revista. Hemos considerado adecuadamente su inclusión dado el interés que, en su momento, suscito y las repetidas alusiones que a el se hacen en el artículo de fondo del presente número. Ofrecemos así a nuestros lectores una más amplia visión del tema. 


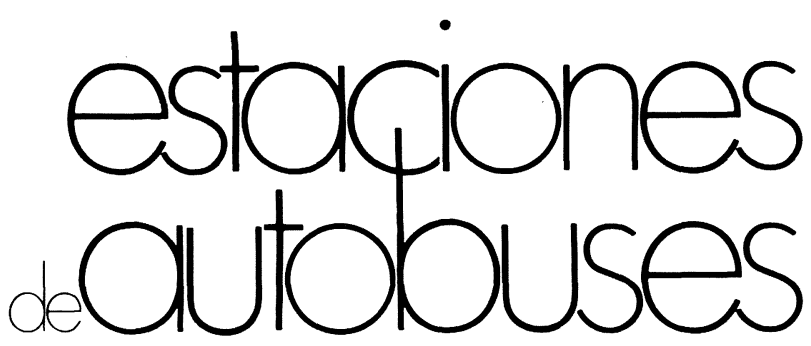

VICENTE OLALLA

\section{DEFINICION Y CONCEP- TOS GENERALES}

Estaciones de autobuses son aquellas instalaciones $\mathrm{que}$ permiten la concentración en un solo punto de las paradas de varias o todas las líneas de transporte público colectivo de viajeros por carretera que tienen en la ciudad comienzo, paso o final de recorrido.

Por lo tanto, y por exclusión, no prestan la función de garaje especializado, ni se utilizan para el transporte de mercancías en camiones o vehículos especializados; si bien es conveniente que en toda estación figure una zona destinada a estancias de autobuses vacíos, preparados a iniciar su servicio público, por ejemplo: a primeras horas del día siguiente después de haber pernoctado en la estación; o bien para albergar durante algunas horas autobuses que se encuentren de paso y que, de otra forma, aparcarían en las calles; y finalmente, para estacionar autobuses dispuestos a reforzar el servicio cuand́do sea preciso. De la misma forma, en tales estaciones puede darse un transporte de mercancías en los autobuses independiente del de los equipajes del viajero, por ejemplo: el transporte de periódicos y de medicinas; deben cumplir dos condiciones: exigir un reparto rápido y regular y ser de pequeñas dimen- siones, es decir, paquetería menuda y en poca cantidad, pues ha de ser transportada en los autobuses además de los viajeros y sus equipajes.

La misión de las estaciones de autobuses es clara: la misma que cumplen las estaciones de ferrocarril o los aeropuertos, referida al transporte público en autobús. Este puede ser suburbano o interurbano, que tienen características distintas; pero las mayores necesidades y exigencias se presentan cuando se trata del transporte interurbano de viajeros: la legislación española, sin embargo, no contempla esta división; únicamente se refiere a las líneas regulares de viajeros que tienen un horario fijo que cumplir.

Los comentarios que siguen se van a referir exclusivamente al proyecto de estaciones de autobuses para servicio interurbano o suburbano de líneas regulares, sin entrar en temas, que pueden ser apasionantes, como el del porvenir del transporte de viajeros en autobús.

\section{LEGISLACION ESPAÑOLA}

La instalación y explotación de una estación de autobuses, al prestar un servicio público dentro del ámbito del transporte de viajeros por carretera, se hallan reglamentadas por la Legislación de
Transporte por Carretera, cuyas disposiciones principales, con los aspectos regulados en cada una, se mencionan a continuación, sin querer, por supuesto, ser exhaustivo:

2.1. Real Orden de 22 de junio de 1929 exigiendo que cada línea de viajeros, en su origen, término y puntos intermedios, tenga un local exclusivamente destinado a los viajeros para proveerse de billetes y esperar la salida de los coches; reglamentando asimismo su uso; así como la existencia de otro lugar para la facturación de equipajes; si bien dejando a criterio de la Dirección General competente sobre los transportes por carretera la designación de los puntos en que es obligatoria la aplicación de las exigencias anteriores.

2.2. El Decreto de 25 de diciembre de 1934 especifica la necesidad de los locales antes mencionados en los puntos de cabecera y final de línea, reglamentando su uso.

2.3. La Orden de la Dirección General de Ferrocarriles y Transportes por Carretera de 21 de enero de 1943 regula la expendiduría de billetes en los despachos oficiales de las líneas.

2.4. La Ley de la jefatura del Estado de 27 de diciembre de 1947 reglamenta el establecimiento de las estaciones destinadas a concen- 
trar las llegadas y salidas de vehículos afectos a servicios públicos, haciendo obligatorio su uso a todas las líneas que no dispongan de instalaciones propias debidamente autorizadas en la fecha de la puesta en servicio de la estación o que no reúnan los requisitos determinados en el Reglamento de esta Ley. Igualmente se impondrá dicha obligación a las líneas que se autoricen a partir de entonces. Esta Ley y su Reglamento de 9 de diciembre de 1949 determinan el procedimiento a seguir en las solicitudes de nuevas líneas, exigiendo la presentación de planos de las instalaciones fijas afectas a la concesión.

El capítulo XII del Reglamento regula la actuación de las iniciativas para el establecimiento de estaciones

En esencia, la iniciativa puede partir de: particulares, Ayuntamiento de la ciudad y Ministerio de Obras Públicas; pero para que actúe uno de ellos es preciso que los mencionados antes no puedan o renuncien a tomar la iniciativa.

Normalmente el primer canalizador de las gestiones es el Ayuntamiento. Primeramente da paso a la iniciativa privada; si ésta falla, el propio Ayuntamiento estudia la construcción de la estación a sus expensas; si no puede o no lo cree conveniente. lo solicita de la Administración Central a través del Ministerio de Obras Públicas. Cuando éste interviene define las características de la estación en función de las necesidades existentes, y, de común acuerdo con el Ayuntamiento. elige el emplazamiento $y$ construye la estación.
También regula la explotación de las estaciones. Cuando éstas son de iniciativa del Ministerio de Obras Públicas deberá efectuarse un concurso al efecto una vez construida la estación, y adjudicarla al concursante que proponga mejores condiciones, dando prioridad al Ayuntamiento y a la Organización Sindical, por este orden. En los demás casos, los promotores pueden explotar la estación por sí o por otras personas o entidades mediante concurso. Se concede la explotación, por un plazo fijado por la Leý en 75 años, que, en la actualidad, parece demasiado amplio.

\section{NECESIDAD}

Son numerosas las razones que existen para demostrar la necesidad de la implantación de una o varias estaciones de autobuses en una ciudad:

3.1. En primer lugar, deben considerarse las exigencias de comodidad de los viajeros y las facilidades que deben encontrar, si bien no suele justificarse la necesidad de una estación por ese solo motivo; existen otros campos de demandas de inversión pública más imperiosa, y la inversión privada o no es rentable en la mayoría de los casos, o encuentra dificultades prácticamente insalvables. Los aspectos más interesantes para el viajero son: comodidad, mejores atenciones, tener a su alcance no sólo la satisfacción de sus necesidades. sino otras atenciones que no tendría en el caso de no existir la estación: facilidad de transbordo a otras líneas; mejor acceso desde su punto de partida; etc.

3.2. En segundo lugar figu- ran las necesidades de la ciudad. En nuestro país existen aún líneas interurbanas de autobuses que, por diversas razones, carecen de instalaciones para el estacionamiento propio de sus vehículos y tienen otras insuficientes para atender al viajero. Por ello los autobuses efectúan, a veces, sus paradas en la calle, provocando entorpecimientos al tráfico callejero de la ciudad tanto de vehículos como de peatones, y congestionando gravemente la zona no sólo por el estacionamiento del propio autobús, a veces en segunda fila, de sus viajeros y equipajes, sino porque provoca la atracción de personas, taxis y vehículos privados que se hacen cargo de los viajeros. Esta carencia de instalaciones ha sido motivada por tres causas bastante claras: falta de medios económicos, en muchos casos; falta de rentabilidad, y el hecho de que, mieritras el tráfico callejero no era importante, el aparcamiento de autobuses en la vía pública no provocaba serias dificultades. Otro factor a tener en cuenta es la circulación de los autobuses dentro de la ciudad, a veces por calles estrechas 0 con recorridos largos, congestionando la red viaria, normalmente tan necesitada de espacio y ya congestionada de por sí.

Es, por lo tanto, muy importante lograr que todos los autobuses de transporte interurbano no tengan que efectuar recorridos dentro de la ciudad por calles que se han vuelto inadecuadas.

La centralización de las paradas permite, además, una potenciación de los transportes colectivos de la ciudad al facilitar el acceso del viajero a ellos y evitar la dispersión de esfuerzos. 
3.3. En tercer lugar figura el interés de la Administración pública, puesto que, centralizando los servicios propios de las estaciones en un solo punto:

- puede m e jor a r notablemente la coordinación del transporte;

- puede tener un mejor y mayor control sobre los servicios prestados por las compañías transportistas;

- evita molestias al ciudadano no usuario;

- potencia de alguna manera los transportes colectivos al aumentar su atractivo frente al transporte particular;

- produce economías.

3.4. En cuarto lugar figura el posible interés de los propios transportistas, ya que:

- consiguen un mejor servicio;

- evitan, o, al menos, disminuyen notablemente sus gastos al repartirse entre todos;

- dan a sus clientes mejores prestaciones;

- pueden atraer nuevos viajeros al mejorar su servicio.

Por consiguiente, la cobertura de estas necesidades del viajero, de la ciudad, de la Administración Pública y de los propios transportistas presenta muchas ventajas, así como también inconvenientes: búsqueda de terrenos adecuados, alteración -en algún sentido- de la urbanización de la zona, etc., y sobre todo de un fuerte desembolso de rentabilidad monetaria incierta, aunque de gran rentabilidad social.
Si existen las necesidades apuntadas y si las ventajas superan a los inconvenientes, puede acometerse la construcción de la estación.

3.5. Con la construcción de las estaciones de autobuses se pretende:

1. Dotar a todas las líneas de viajeros de terminales adecuadas. Las empresas pequeñas no pueden tenerlas por razones económicas; las grandes, sin embargo, suelen disponer de terminales propias, llegando incluso a poseer verdaderas estaciones de gran simultaneidad de salidas o llegadas; pudiendo, no obstante, acogerse a las mismas prerrogativas de uso de la estación comunal que las demás empresas.

2. Conseguir una coordinación mejor entre las diversas líneas.

3. Facilitar al viajero sus operaciones, rodeándole de las mayores comodidades posibles.

4. Evitar, en lo posible, las consecuencias molestas.

\section{NUMERO}

Invirtiendo un poco el orden lógico de la exposición, trataremos del número de estaciones de cada ciudad.

No parece que exista un límite para el número de estaciones de una ciudad; únicamente puede decirse a priori que es pequeño. Depende de cuatro factores principalmente:

1. Capacidad $m$ á x i m a de una estación.
2. Población.

3. Forma y extensión de la ciudad.

\section{Vías de comunicación.}

El primer factor tampoco está definido; no obstante, es aconsejable que una estación no sobrepase las 40 ó 50 salidas y llegadas simultáneas de autobuses. Este orden de magnitud ha sido fijado por nuestra experiencia personal en capitales de provincias españolas. Parece que señala un límite máximo de la superficie de terrenos disponibles.

Igualmente, al indicar una gran demanda de transporte de viajeros $y$, por lo tanto, una grann extensión de la ciudad, no causa mayores problemas la implantación de dos estaciones o más, puesto que cada una tendrá una capacidad aceptable, superior al mínimo estimado, y pueden llegar a ser rentables por sí mismas.

El segundo factor suele actuar simultáneamente con el primero. En una ciudad similarmente extendida en varias direcciones y de gran población puede ser conveniente instalar varias estaciones: las distancias dentro de la ciudad son grandes y no se aumentan excesivamente las duraciones de los trayectos de los viajeros hacia las estaciones; los transportes colectivos son igualmente potentes y sustituyen favorablemente a los recorridos de los autobuses por la ciudad.

Un claro ejemplo en España es el de Madrid. Su Ayuntamiento tiene la intención de construir cuatro estaciones de autobuses, cuya situación esté ligada claramente a las principales carreteras de acceso, puesto que, además 
de actuar el factor de población y el de la forma de extensión de la ciudad, también actúa el de las vías de comunicación, dado que éstas se hallan muy claramente separadas $y$ es muy importante que los autobuses no entren profundamente en el casco de la ciudad.

En cuanto al tamaño mínimo de las estaciones, pensamos que su capacidad debe sobrepasar las 10 simultaneidades de llegadas o salidas. Dado que las estaciones no suelen ser rentables por sí mismas, si el número de personas que la utilizan es suficiente pueden instalarse comercios: de tabacos, periódicos, libros, bebidas, cafetería, restaurante, teléfonos públicos, bancos o cajas de ahorro, boutiques, peluquerías, etc., cuya superficie no es muy grande comparada con el resto y cuyos productos de su alquiler o compra pueden ayudar a hacer rentable la explotación de la estación, además de proveer de facilidades al usuario. Por ello, al ser pocos los viajeros que utilicen la estación, su explotación deja de ser rentable con seguridad.

\section{EMPLAZAMIENTO}

La situación de una estación de autobuses debe elegirse teniendo en cuenta:

1. Su facilidad de comunicación con el núcleo de la ciudad. Por este motivo los terrenos elegidos deben ser lo suficientemente céntricos para minimizar al menos el tiempo necesario para llegar a la estación desde cualquier punto de la ciudad.

2. La proximidad a rutas de acceso o comunicación fácil dentro de la ciudad. Con ello se limitan los recorridos de los autobuses por la red viaria, aliviándola de esa carga y no congestionando $\mathrm{s} u \mathrm{~s}$ calles. A la vez disminuye el tiempo necesario para que el autobús Ilegue a la estación.

3. Sus posibilidades de comunicación con los medios de transporte colectivo urbano: tranvías, metropolitano, líneas de autobuses urbanos, etc.

4. $\mathrm{Su}$ comunicación c o n estaciones ferroviarias: prefiriéndose su cercanía. Este punto es muy importante, ya que el transporte por autobús suele ser normalmente complementario del transporte por ferrocarril.

5. Los planes de desarrollo de la ciudad. Puede elegirse una situación algo descentrada pensando que su crecimiento controlado haga conveniente la instalación de otra estación complementaria.

6. Las condiciones climatológicas de la zona, especialmente las pluviométricas y la posibilidad de formación de hielo.

7. Otros tipos de condiciones no mencionados, como, por ejemplo, su proximidad a una zona comercial, que puede tener peso específico suficiente para decidir entre dos emplazamientos similares.

En cualquier caso es fundamental estudiar cuidadosamente el acceso de un autobús de cualquier procedencia a la estación. Su recorrido dentro de la ciudad debe hacerse siempre por calles amplias y no congestionadas.

\section{CAPACIDAD}

Una vez decidida la necesidad o conveniencia de la instalación de una estación de autobuses, el primer paso a dar es la determinación de su capacidad. Para ello, antes han de hacerse algunas consideraciones sobre el tipo de servicio a prestar.

En España las estaciones de autobuses se justifican principalmente para el tráfico interurbano sin distinción entre diversas longitudes del recorrido, puesto que es el más necesitado de instalaciones centralizadas y además la duración del viaje es francamente superior a los posibles desplazamientos posteriores del viajero en la ciudad. E! tráfico de autobuses suburbanos, dada su corta duración del recorrido de la línea, pierde la mayoría de sus ventajas al tener que rendir viaje en un solo punto de la ciudad.

Finalmente, al tráfico discrecional de viajeros, es decir, no sometido a regulación horaria ni de recorrido, le ocurre lo mismo que al suburbano. Por ejemplo: al transporte turístico le interesa recorrer varios monumentos o lugares pintorescos deteniéndose en numerosas ocasiones, y obligarle a terminar en la estación antes de iniciar el recorrido por la ciudad significaría incluso hacerle desaparecer.

No obstante lo dicho, a veces no existe una clara diferenciación entre viajes interurbanos y suburbanos. Por ejemplo: en la ciudad de Las Palmas de Gran Canaria, por ca- 
recer de transporte ferroviario, y existir esa gran ciudad con doscientos setenta mil habitantes en una isla de cuatrocientos mil, el transporte colectivo de viajeros por carretera tiene una clara calificación de suburbano, a pesar de que alguna de las distancias recorridas tienen importancia, siendo superiores a los cien kilómetros.

El uso de la estación, al menos en su mayor parte, se limita al tráfico de líneas regulares de viajeros, y éstas son conocidas por regir horarios inflexibles una vez estatuidos. Por este motivo se tiene siempre el catálogo de líneas, sus movimientos y el número de autobuses que precisan. Así se conocen las necesidades actuales; para las futuras puede llevarse a cabo una prognosis de la demanda, aunque a veces no es imprescindible. Sí debe establecerse un coeficiente de mayoración para prever el aumento de la demanda, en función del grado de desarrollo comarcal y ciudadano y de la política general de los transportes. Ello es así porque la capacidad de una estación puede ser bastante flexible, aún después de construida.

En lo que sigue apar€cerá la palabra dársena, que ha sido tomada prestada por analogía del lenguaje portuario. Su definición aplicada a las estaciones de autobuses puede ser: estácionamiento resguardado de la circulación general y dispuesto para la carga y descarga de los viajeros de un autobús. Así, pues, un índice de la capacidad de una estación lo da el número de dársenas: a más dársenas, más capacidad; pero queda otro índice: el aprovechamiento de cada dársena, íntimamente li- gado al tiempo de estancia del autobús en ella. Este tiempo, asimismo $\mathrm{v}$ a $\mathrm{r}$ i a b le dentro de límites, puede situarse como mínimo en 10 minutos para vaciarse de viajeros y en 20 para llenarse el autobús. Este último índice sólo entra en función con sus valores mínimos de tiempo en las horas punta, como es natural. Por otra parte admite una corrección, deducida de la experiencia de cada lugar, pues las salidas de los autobuses $p$ ueden efectuarse exactamente a la hora prevista, pero no así las llegadas, que dependen de numerosos factores: averías, accidentes, estado de la circulación, etc., que son aleatorios en su mayor parte. Por ello, normalmente, puede considerarse la cifra de los 20 minutos como útil tanto para salidas como para llegadas.

Existe, por último, otro aspecto a tener en cuenta en la determinación del número de dársenas: para el viajero que utiliza frecuentemente una línea de autobuses le resulta muy cómodo saber que su autobús sale siempre de la misma dársena o, cal menos, de la misma zona. Esto se da principalmente en líneas de tipo suburbano, donde, como hemos dicho antes, es más importante la frecuencia que el propio horario. Ello lleva a agrupar algunas líneas en una zona, formando prácticamente una estación dentro de otra estación. También parece interesante agrupar las salidas por un lado y las llegadas por otro, debiendo, naturalmente. solaparse, porque no suelen coincidir las horas punta de salidas con las de llegadas y. por lo tanto, la capacidad máxima de la estación no debe ser la suma de las necesidades máximas de sali- das y de las n'ecesidades máximas de llegadas.

Una vez manejados y ponderados estos datos, se confecciona un horario de necesidades que da el máximo número de dársenas. La cifra obtenida se multiplica, a continuación, por un coeficiente de mayoración, que puede oscilar entre 1,2 y 1,5 según el grado de desarrollo de la ciudad, su comarca y sus transportes, para obtener el número necesario de dársenas.

Con todo ello no queda definida, no obstante, la capacidad máxima, puesto que, una vez alcanzada la saturación del empleo, cabe el recurso de modificar leve, pero adecuadamente, el horario de algunas líneas para rebajar la punta de la demanda. Igualmente aumenta la capacidad si no se adscribe una dársena fija a una línea determinada; en este caso debe instalarse un pupitre de mando que domine la zona de dársenas y establecer un sistema que permita dar instrucciones rápidas a los autobuses para que desalojen su dársena o vayan a la que se determine en cada momento.

\section{TIPOS}

Por su finalidad pueden dividirse las estaciones en su totalidad o en parte: para servicio suburbano o para largo recorrido. En el primer caso debe predominar la agilidad: el autobús ha de efectuar las menores maniobras posibles, y su estancia en la dársena puede ser tan corta como la necesaria para vaciarse por una puerta mientras se llena por la otra. En el segundo caso no es importante el tener que hacer maniobras. Prima, sobre todo, el lograr la menor superficie necesaria. 
Por su forma pueden dividirse, según la disposición de las dársenas, en: cóncavas, convexas, continuas y discontinuas. Esto viene obligado por las características del terreno disponible y el arte del proyectista. Dentro de ellas deben preferirse las convexas sobre las cóncavas, ya que éstas necesitan normalmente más espacio para la maniobra de los autobuses y ésta es más complicada.

También pueden dividirse en: de una altura o de más alturas, según los planos utilizados, tanto por los viajeros como por los autobuses.

\section{DISPOSICION DE DARSENAS}

Existen varias cualidades a tener en cuenta para elegir el tipo de dársena más adecuado en cada caso:

- acceso del viajero al autobús;

- sentido de circulación;

- maniobras necesarias del autobús:

- superficie ocupada por cada dársena.

8.1. Acceso del viajero y sentido de circulación: En España la circulación es "a derechas", por lo que los autobuses presentan más facilidad para acceder por su lado derecho. Debido a ello, aunque puedan darse ambos sentidos de circulación, las aceras para acceso del viajero al autobús deben siempre situarse al menos por su derecha; y dentro de este criterio, el hacerlo únicamente por la puerta delantera sólo o por ambas será cuestión de la superficie y forma del terreno disponible.
8.2. El sentido de circulación, no obstante, puede ser cualquiera dentro de la estación, ya que su elección depende únicamente de factores intrínsecos a ella.

8.3. Las maniobras del autobús condicionan muy fuertemente el proyecto, puesto que de ellas depende fundamentalmente la superficie a ocupar. Primeramente deberá evitarse que el tubo de escape esté orientado hacia el viajero que espera para que éste no tenga que sufrir las consiguientes molestias cuando el autobús se ponga en marcha o cuando caliente motores, aunque esto último debiera hacerse en otro lugar; así, debe ser obligatorio el aparcar de frente y no retrocediendo. En segundo lugar queda el tema de las maniobras necesarias al llegar y al salir: el tener que hacer ambas supone pérdida de tiempo, aunque puede evitarse en la mayoría de los casos limitándolas a una e, incluso, deberán evitarse ambas si la rapidez del servicio lo requiere como en tráfico suburbano de cądencia muy rápida. Finalmente, por razones de comodidad, debe elegirse la maniobra a la salida del autobús sobre la de entrada.

8.4. Superficie ocupada: Para proceder a su determinación deben estudiarse previamente las disposiciones más convenientes.
En las figuras se muestran algunas de las disposiciones más usualmente utilizadas. En todas ellas se supone existe una acera para que el viajero no pise el pavimento de rodadura, que suele estar manchado de aceites y grasas por muy bien que se limpien y para que la altura a salvar desde el estribo sea mínima. Igualmente en todas el autobús, como mínimo, tiene una puerta de su costado derecho sobre la acera, no utilizándose el costado izquierdo, aunque en alguna disposición pueda emplearse éste.

La disposición de la figura 1 está prevista para que el autobús ocupe aparcando en línea el menor espacio posible, si bien a costa de tener que hacer maniobra tanto al entrar como al salir.

En la figura 2 se muestra una posible solución para no tener que hacer maniobras ni al entrar ni al salir, con el menor espacio posible, que, naturalmente, es algo mayor que el anterior.

La disposición de la figura 3 está prevista para que el autobús no tenga que efectuar maniobra para aparcar, pero es la que más superficie necesita.

La figura 4 es una variante de la figura 2, que, en un intento 

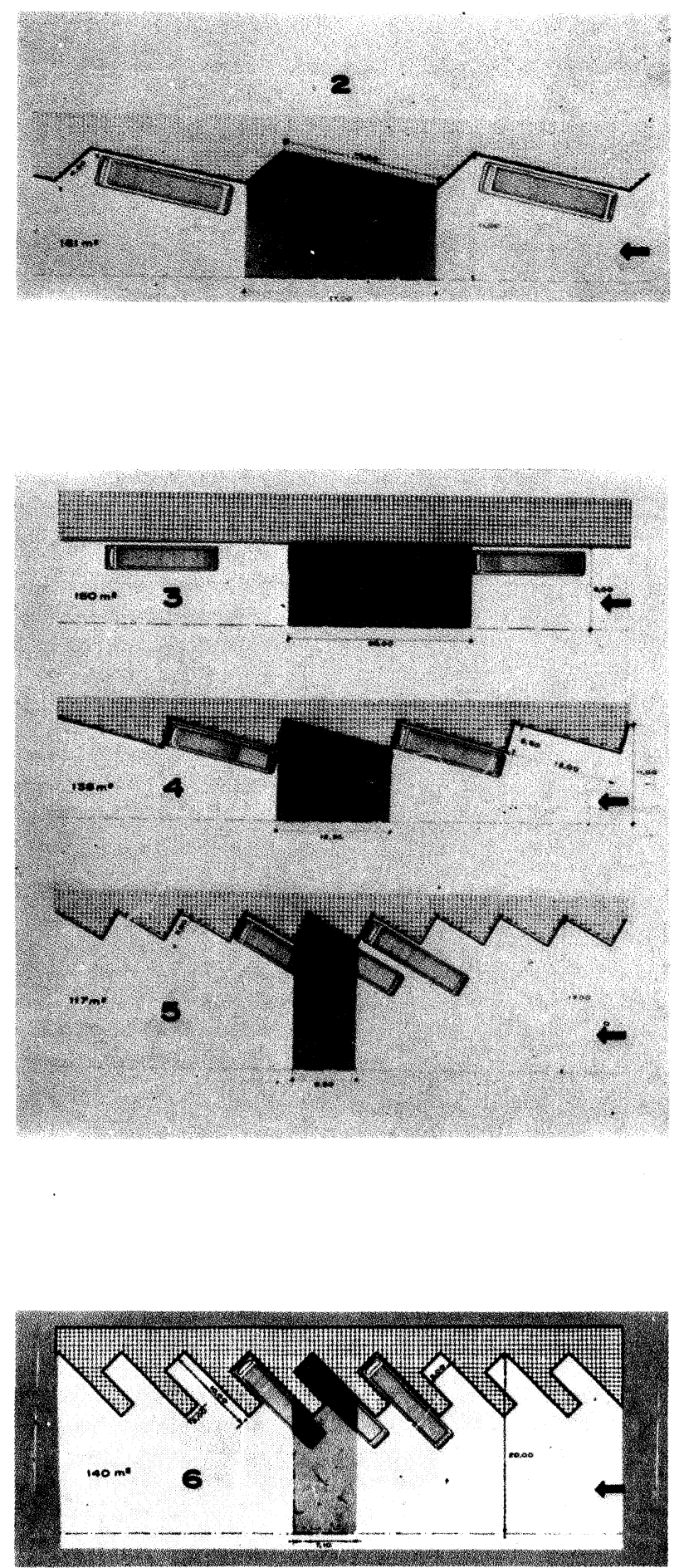

de economizar espacio, obliga a realizar maniobra a la salida.

La figura 5 es una extrapolación de la anterior, pues además sacrifica el uso de la puerta trasera del autobús.
La figura 6 presenta una distribución de concepto completamente distinto. De las que sólo necesitan maniobra al salir y emplean las dos puertas es la que menos superficie presenta, y siendo además la que menos longi- tud precisa, con lo que disminuye la distancia a recorrer por el viajero. La superficie necesaria depende del ángulo que el autobús forma con la acera, siendo mínima para un ángulo ligeramente superior a los $45^{\circ}$.

Todas las disposiciones mostradas hasta ahora se basan en el sentido "a derechas" de circulación del autobús, considerando necesario su aparcamiento sobre el costado derecho.

Si, por cualquier razón, se precisara circular a izquierdas, la disposición 6 se adaptaría, necesitando únicamente algo más de superficie, sobre todo de maniobra del autobús. Combinando dentro de una estación ambos sentidos de circulación puede lograrse la menor superficie total posible.

En resumidas cuentas: los dos tipos que pueden considerarse más convenientes en general son los mostrados en las figuras 4 y 6 , ambos de similar necesidad de espacio. privando el, primero con la variante de la figura 2 cuando se precisen maniobras muy rápidas o se disponga de poco espacio en anchura, y el segundo cuando se quiera acortar las distancias a recorrer por el viajero en los andenes.

\section{EQUIPAJES}

9.1. El viajero puede transportar equipaje en la mano, si es pequeño y manejable, y en el portaequipajes del autobús, si es grande. En este caso debe preverse su manipulación por el personal operario de la estación o por el de la empresa transportista. 
El viajero que va a partir debe entregar su equipaje en un mostrador, donde, una vez unido a los que tengan el mismo destino, será transportado con ellos al autobús y allí cargado. Estas operaciones deben ser muy sencillas y rápidas con el fin de evitar prolongaciones en la ocupación de las dársenas. Se necesita, por lo tanto: un lugar de recogida, almacenamiento y clasificación de equipajes, y un sistema para su transporte al vehículo.

El almacén debe ser amplio para albergar estanterías que permitan el almacenado del equipaje y además tener espacio suficiente para consigna, que puede estar inmediatamente situada para ahorrar personal. Hay que tener en cuenta que un autobús puede transportar de 8 a $10 \mathrm{~m}^{3}$ de equipaje, lo que permitirá dimensionar el local.

9.2. El problema del transporte del equipaje desde el almacén al autobús presenta varias soluciones:

1. Mediante carretillas o c i n t a s transportadoras que lleguen a la vertical del autobús por encima de él o a nivel del suelo.

2. Que el viajero lleve su propio equipaje directamente al autobús, donde será manipulado por el personal del mismo.

3. Que el autobús, previamente a su recogida de viajeros, pase por una zona distinta reservada al efecto para hacerse cargo del equipaje.

La primera solución parece la más deseable en condiciones normales, puesto que:

- evita molestias al viajero;
- centraliza las operaciones;

- facilita el almacenamiento del equipaje en el autobús;

- garantiza el cumplimiento del horario;

- evita molestias al personal del autobús.

Puede tener dos modalidades: que el transporte se haga a distinto nivel del autobús o al mismo. Los autobuses de diseño moderno procuran situar su portaequipajes en su parte inferior, porque así logran dos objetivos importantes: rebajar la posición de su centro de gravedad, con lo cual se hacen más estables y presentan menor superficie al avance contra el aire; ambos muy importantes, dadas las velocidades usuales hoy. Por ello parece aconsejable que, si no existe una demanda importante de transporte de equipajes. éste se efectúe al mismo nivel que el autobús, por ejemplo: con carretillas eléotricas. Así se ahorra mano de obra y se evita transportarlo en vertical. Por otra parte se ha constatado la tendencia a disminuir el equipaje que el viajero lleva consigo en sus desplazamientos.

Por supuesto, en caso de ser importante el transporte de equipajes, éste requeriría una solución a distinto nivel.

La segunda solución apuntada es la más cómoda para la entidad explotadora de la estación, ahorrándose jornales. Fuera de las horas punta parece una solución aceptable en su conjunto y de hecho se da en la realidad. Al viajero no le molesta demasiado $y$; a veces, le gusta ver cómo su equipaje es tratado por el propio transportista.
La tercera solución es la que más espacio necesita, del que normalmente se carece, y que, si existiera, debería tener mejor destino.

\section{EDIFICACION}

Existen tres partes claramente diferenciadas por su destino, aunque en la realidad no es necesario que esto ocurra. No obstante, puesto que los tratamientos pueden ser distintos parece razonable diferenciarlos.

10.1. La zona de movimiento de viajeros, que debe estar aislada de los autobuses, ha de tener un tratamiento elegante, ser de materiales nobles, de fácil conservación y durabilidad, ser espaciosa y bien distribuida para que el viajero, a simple vista, encuentre las instalaciones que precise y se sienta cómodo.

Los suelos pueden ser de terrazo, material que en España ha alcanzado un alto grado de desarrollo tanto técnica como estéticamente. En las paredes suelen emplearse piedras calizas pulidas e incluso mármoles, al menos en sus partes bajas.

El principal problema que se presenta al proyectista, aparte de lograr una distribución armónica y correcta de las diversas dependencias, es el de la iluminación natural del edificio, debido a su extensión. Existen dos tipos utilizados prácticamente por igual en las realizaciones existentes: iluminación cenital, con sus diversas variantes, empleadas en La Coruña y Salamanca como solucicnes representativas, e iluminación lateral, dotando de alturas distintas a los diversos loca- 
les, tal como se ha hecho en Valladolid y Avila, por ejemplo.

Otro problema es el de la estética arquitectónica, pues se trata normalmente de edificios bajos y muy amplios.

10.1.1. En el edificio de viajeros deben existir, como mínimo, las siguientes dependencias:

- Vestíbulo amplio de acceso y de "pasos perdidos".

- Taquillas, cuyo número depende del de empresas transportistas que van a utilizar la estación, con un margen debido para posibles ampliaciones. Este número no es muy rígido, pues existen empresas que explotan numerosas líneas de importancia y otras que sólo explotan una y de escasa entidad.

En principio, un orden de magnitud puede ser el del número de dársenas, porque si las empresas deben compartir un a dársena, también deben poder compartir una misma taquilla. Esta cifra es correcta donde existe una atomización media o grande del transporte, como ocurre en Salamanca y Valladolid, que tienen unas 30 dársenas, $y$ es notoriamente excesiva, como ocurriría en Las Palmas, que puede necesitar unas 40 a 50 dársenas y sólo dos empresas transportistas, cooperativas de empleados en este caso.

Las dimensiones de las taquillas deben ser las mínimas posibles, $1,50 \mathrm{~m} \times$ $+2,50 \mathrm{~m}$, para evitar se destinen a oficinas, y correlativas, no sólo para que el viajero identifique su situación fácilmente, sino para poder unir algunas entre sí, si fuese necesario.

- Zona de espera y sala de espera. Parece conveniente distinguir entre espera corta y espera larga, pues existe demanda para las dos. La primera puede hacerse en zonas abiertas al tráfico del público, y la segunda debe estar apartada de él y tener comodidades extras, como butacones, calefacción, músịca ambiental, etc. La primera puede resolverse empleando soluciones tipo aeropuerto y la segunda debe preverse en salas independientes.

- Recogida, almacenamiento y entrega de equipajes.

- Consigna y facturación, que pueden simultanearse con las anteriores para ahorrar personal.

- Oficina de correos, exigida por la legislación española, que debe tener un buzón a la calle y puede necesitar acceso independiente desde ella.

- Aseos y servicios: con lavabos, urinarios, WC y piletas para la limpieza: debe preverse en ellos la instalación de un sumidero de recogidas de aguas de limpieza o que se hayan derramado $y$, por supuesto, mucha ventilación.

- Oficinas, tanto para la dirección de la estación como para los concesionarios,de las líneas de transporte, donde éstos puedan llevar su contabilidad, hacer arqueo, guardar sus billetes y atender reclamaciones del público únicamente, pues sus oficinas generales no deben tener cabida normalmente en la estación.
- Locales comerciales, tales como cafetería e incluso restaurante, puesto de periódicos, tabacos, banco, etcétera, además de los cuales puede existir una muy variada clase de locales a los que debe poder acceder el público desde dentro. Pueden instalarse, asimismo, otros accesibles únicamente desde la calle que, además de ayudar a hacer rentable la explotación, la convierten en más atractiva. Normalmente la proliferación de locales no debe ser obstáculo para la estación si se proveen de circulación independiente de sus clientes. Pueden llegar a formar un centro comercial.

- Botiquín, centro de primeros auxilios médicos.

- Local para la policía e, incluso, un pequeño calabozo mientras el detenido espera a que le conduzcan a la comisaría.

- Oficinas de la Administración, para controles e inspecciones.

- Oficina de información al público, aunque se tiende a su desaparición para ahorrar jornales y porque la información escrita y la aportada mediante el sistema de megafonía la hace innecesaria.

- Teléfonos públicos, normalmente mediante aparatos accionados por monedas.

\section{ZONA DE AUTOBUSES}

La segunda zona mencionada anteriormente es la de autobuses, que incluye: las dársenas, zona de maniobra y aparcamiento, aceras para el público, control y portería. 
Normalmente puede encasillarse en edificación industrial $y$, por lo tanto, distinguirse del edificio de viajeros mediante el empleo de materiales menos nobles y tratados de otra manera.

El problema de la extensión es aquí mucho mayor, ya que se necesitan superficies 2 a 4 veces superiores, por lo que sólo el problema de su ubicación ya es muy importante. Normalmente no se cubre toda la superficie, sino la zona de aceras, pero únicamente para resguardar al viajero del sol y la lluvia. Existen casos excepcionales en que por la crudeza del clima así se ha hecho como en Avila y Santiago de Compostela: en la primera por el frío, en la segunda por la humedad.

La superficie necesaria oscila entre 200 y $250 \mathrm{~m}^{2}$ por dársena, y depende del tipo y número de dársenas y de la forma del terreno disponible.

Sus diversas formas han sido mencionadas antes $y$ no es preciso extenderse más sobre ello.

El aprovechamiento del número de dársenas es uno de los temas más importantes que restan por tratar puesto que influye notablemente en el diseño. En los proyectos realizados hasta ahora se ha procurado, como premisa inicial, que el autobús en su recorrido dentro de la estación pase por delante de todas y cada una de las dársenas 0 , al menos, por las de un grupo si así están clasificadas, con visibilidad suficiente para ver si una dársena está ocupada o vacía. Entonces se sitúa una caseta de control, como se ha hecho en Valladolid, Avila y Salamanca, desde donde se pueda dominar toda la zona de dársenas y la entrada a la estación; si esto no fuera posible, habría necesidad de instalar un circuito cerrado de televisión, por ejemplo, u otro sistema que supla la falta de dominación total visual. En la caseta se ha colocado un panel de mando sobre mesa con un esquema de las dársenas; en cada una de ellas se sitúan dos luces piloto: verde y roja, y una clavija de tres posiciones: apagado, luz roja y luz verde. Los pilotos instalados en serie cada uno con su correspondiente luz del mismo color en el semáforo colocado en su dársena. Inicialmente se ponen en rojo todas las luces, tanto de la mesa como de las dársenas, estén o no ocupadas. El autobús, al empezar su recorrido delante de las dársenas, se encuentra todas las luces en rojo, menos una que está en verde porque el controlador así lo ha dispuesto desde la mesa. El autobús ocupa esa dársena y el controlador, una vez que lo ha comprobado, cambia el semáforo a rojo.

El sistema permite ordenar el momento de la partida de un autobús, pues basta poner en verde el semáforo de la dársena ocupada, que es la señal de mando que ordena al conductor poner en marcha el vehículo.

El procedimiento está suficientemente confrontado en su empleo y es tan simple que ha dado resultados perfectamente satisfactorios.

\section{ILUMINACION}

La iluminación del edificio puede ser del tipo convencional, empleándose normalmente luz fluorescente en tubos del tipo luz de día de 2.000 lúmenes de emisión. La inten- sidad alcanzada es también la normal: entre 200 'y 250 luxes; esta última en las escaleras y zona de taquillas sobre todo y aquélla en zonas de escasa importancia. No obstante, las luminarias se ordenan en dos o tres circuitos de encendido independientes para tener dos niveles de luz si se considera necesario.

Por ser un edificio público debe proveerse de señalización e iluminación de emergencia mediante luz incandescente según se exige en la legislación vigente.

En la zona de maniobra la iluminación puede ser análoga a la de las calles circundantes: de 25 a 30 luxes. $Y$ en las aceras para los viajeros puede bastar menos de 100 luxes.

Como siempre, las luminarias empleadas deben ser de fácil conservación y reposición.

Tampoco existe inconveniente en mezclar esta luz con el, empleo de otras: por ejemplo de sodio o mercurio a alta presión, si los techos son muy altos como ocurre en los vestíbulos de las estaciones de Avila y Salamanca, por ejemplo.

El suministro de energía se procura sea a alta tensión, instalando una estación transformadora propia con su aparellaje y cuadros.

\section{INSTALACIONES}

Además de las instalaciones mencionadas, es conveniente existan otras cuya enumeración, sin ser exhaustiva la lista, puede ser la siguiente:

- Tomas de energía eléctrica para conectar aparatos. 
- Red de calefacción, imprescindible en la mayoría de los casos, que normalmente se da mediante radiadores de agua calentada al quemar fuel-oil en calderas propias, lo que exige normalmente una caldera, depósitos, bombas, etc.

En los vestíbulos se ha ensayado instalar unos aerocalentadores que, en esencia, son unos impulsores de aire al que previamente se puede calentar o no empleando el mismo agua del resto de la calefacción.

- Refrigeración o aire acondicionado, aunque normalmente no se emplea. En los vestíbulos pueden utilizarse los aerocalentado: res impulsando aire sin calentar, a la temperatura ambiente, para aprovechar el efecto refrescante que produce la simple renovación del aire. En nuestras experiencias han dado buenos resultados, si bien es difícil anular totalmente el ruido de los motores.

- Megafonía, mediante altavoces de $40 \mathrm{~W}$ usualmente dispuestos en columnas exentas y que normalmente se emplean para transmitir la voz humana y el sonido de aviso producido por un timbre electrónico. Eventualmente puede transmitirse música.

El locutor es el propio controlador desde su pupitre de mando. Tiene dos potencias para regular separadamente el sonido de interiores y en exteriores.

- Cronometría, puesto que dada la extensión de la estación y sus numerosas áreas independientes es conveniente colocar varios relojes, y entonces es preciso señalen la misma hora; para ello se instala normalmente un reloj-patrón de cuarzo que telemanda eléctricamente los demás secundarios.

- Red de teléfonos, incluso con centralita que puede ser semiautomática, aparte de los aparatos accionados con monedas.

- Señalización visual de todos y cada uno de los lugares de interés, así como de la numeración o identificación de dársenas.

- Abastecimiento de agua corriente e, incluso, de agua caliente.

- Saneamiento, con un separador de grasas al final para que éstas no lleguen al alcantarillado de la ciudad.

\section{INSTALACIONES COMPLEMENTARIAS}

La tercera zona mencionada antes puede albergar instalaciones como:

- De suministro de carburante, que debe estar algo separado del flujo de autobuses, con aparatos medidores y depósitos enterrados que deberán cumplir la legislación propia.

- Pequeñas instalaciones de lavado, engrase y revisión de los autobuses en las que pueden efectuarse las pequeñas operaciones; pero no las grandes, que habrán de hacerse necesariamente fuera de la estación.

- Zona de estacionamiento extra de vehículos, con unos 60 a $70 \mathrm{~m}^{2}$ por autobús, bien para estancias nocturnas, bien para reforzar el servicio en su momento o esperar su salida algún tiempo más tarde.

\section{RENTABILIDAD}

El coste de la construcción de una estación de autobuses de la calidad que se ha mostrado aquí puede alcanzar en la actualidad la cifra de 3,5 a 4 millones de pesetas por dársena. Esta cifra debe tomarse como un orden de magnitud, pues puede variar con la forma del terreno disponible, de los accesos necesarios y del tipo de estación: si se desarrolla en una o varias alturas, por ejemplo.

El terreno no puede valorarse a priori, pues éste sí es muy variable, dependiendo de:

- la propia ciudad;

- planes urbanísticos;

- situación;

- procedencia; etc.

15.1. Los ingresos de la estación pueden ser de varias procedencias:

- de un gravamen sobre cada billete expedido en líneas que usen la estación; éste debe ser muy pequeño puesto que, en nuestro caso, se busca la rentabilidad social más que la económica; sin embargo, no debe desaparecer porque indudablemente el viajero se beneficia de las instalaciones;

- de un "derecho de paso" cobrado a cada autobús que entre en la estación;

- del alquiler de los locales comerciales; de ahí, el interés de potenciarlos;

- de la publicidad autorizada; 
- del alquiler de las oficinas a los transportistas;

- de la venta de carburante;

- etcétera.

15.2. Entre los gastos que se ocasionan durante la explotación figuran:

- amortización de las instalaciones;

- cánones e impuestos;

- gastos de conservación;

- consumos: eléctrico, de calefacción;

- nómina del personal.

En conjunto, el tema de la rentabilidad merece algunas reflexiones.

Vaya por delante que los gastos iniciales: de adquisición del terreno, construcción de la estación y de primer establecimiento son lo suficientemente elevados como para que, con las fuentes de ingresos apuntadas antes, difícilmente hagan adecuadamente rentable la estación en ningún caso. No obstante, la rentabilidad social es muy alta, motivo por el que la Administración Pública no duda en acometer su construcción, antes que autorizar un gravamen fuerte sobre el viajero.

En cambio, la explotación sí puede ser muy rentable, naturalmente dándose las debidas condiciones.

$\mathrm{El}$ ingreso mayor es el que procede de los gravámenes sobre los billetes aun sin sobrepasar una cuantía razonable. En segundo lugar figura el procedente de los alquileres de locales comerciales, si existen en número suficiente y están adecuadamente situados. En tercer lugar, el derivado del uso de las instalaciones con recaudación propia: consigna, billetes de andén si éste existe, alquiler de taquillas, etc. Mención aparte merecen los ingresos por autorización de publicidad que, sin abusar de ella, alcanzan también cifras sustanciosas.

Entre los gastos el más notable es el de gastos generales $y$, dentro de él, el concepto de sueldos del personal, por lo que es muy importante estudiar la forma de explotar la estación, lo que, indudablemente, debe preverse desde el propio proyecto. Es posible lograrlo con una plantilla fija de 6 a 8 personas.

También debe incluirse un presupuesto de conservación no rutinaria para hacer frente a reposición de elementos gastados, a pintura general, etcétera.

Otro aspecto que influye notablemente en la "explotación es el de las características de la empresa concesionaria. 